\section{Socio-Economic and Cultural Aspects of Ageing in Nepal}

\section{Dr. Rishi Keshab Raj Regmi}

Introduction

The problems posed by the aged appear to assume increasing importance of late. The United Nations convened a World Assembly on Ageing in 1985 to discuss the problems. There was a move to declare the year 1982 as the year of the aged. The idea was to focus the attention of the member countries on the problems.

In the developed countries of the west the problems posed by the aged have assumed serious proportions and therefore probably the thinkers in these countries have become aware of them. These thinkers.have drawn the attention of the other count ries to this problem area. A problem which is serious in one country may not be regarded so in other countries: they may have other problems which have to be given a higher priority. But this aspect must be given due importance as Nepalese society too is fast transforming its structure and function and ageing has become an increasing problems for many.

*Head, Department of Sociology/Anthropology, Tribhuvan University, Kathmandu, Nepa!.
Accordingly, the present paper discusses the problems in its Nepalese context and perspective.

\section{Nepalese Tradition in Caring For Aged}

The Pluralistic, multireligious and mosaic culture of Nepalese society has adopted and adjusted with the culminating onslaught of western life styles and culture. The villages are no longer beset with old aged cultural and social tradition. There are signs of transformations in every sphere of social life, be it of social values, life patterns. customs and usages. The modern amenities and materialistic development has suppressed outwardly the foundation of spirituality, the basis of our society.

\section{The Population Situation}

In Nepal around 93 percents of the population live in rural areas Population has gone up over the years with a proportionate increase in aged segment. There is also a simultaneous and growing trend of population shift from the rural to urban areas.

Percentage distribution of the total population by broad age-groups. Nepal census 1952/54-81.)

\begin{tabular}{c|rrrr}
\hline Age & \multicolumn{5}{|c}{ Year } \\
\cline { 2 - 5 } Group & $1952 / 54$ & 1961 & 1971 & 1981 \\
\cline { 2 - 5 } & 38.44 & 39.87 & 40.46 & 41.35 \\
$15-24$ & 18.48 & 16.96 & 17.45 & 17.70 \\
$25-59$ & 37.65 & 37.64 & 36.47 & 35.21 \\
$60+$ & 4.98 & 5.19 & 5.62 & 5.74 \\
Not stated & 0.45 & 0.34 & & \\
\hline Total & 100.00 & 10000 & 100.00 & 100.00 \\
\hline
\end{tabular}

Out of the total population of 17 millions in Nepal, children 10 to 14 years and youth ( 15 to 24 ) together form nearly 60 per cent of total population. The total elderly or aged popula. tion in Nepal in 1981 is only 5.74 percent. 
One of the outstanding features of the Nepalese population is found to be the nearly static age structure co-existing with a rapid increase in the size of the population. Even though the age distribution of population of Nepal has been nearly static there ware son 3 small but notable chages. These changes are as follows: there has bien a slow but steady increase in the proportion of children below 15 years and of elderly persons aged 60 years and above with corresponding decline of the proportion of the population in the adolescent and adult ages particularly in the adult age group ( 25 to 59 years). The principle cause of this rise in the population under age 15 was probably the decline in infant and child mortality and in the proportion of those aged 60 years and above in the total population may be attributed to an increase in life expectancy associated with over all improvement in the mortality situation during last three decades (1952/54-81)

The proportion of older people of age 60 years and above is higher in rural than in urban areas. Nepal suffers a heavy burden of dependency particularly at young ages. Today roughly about 100 persons in the production age have to support 89 dependents in terms of food, clothing, health education and like. This is in contrast to the situation in the developed countries where there are only about 45 to 65 dependents per 100 persons of the productive groups.

\section{The Terms Elderly, Aged. and Old: An Analytical Understanding}

As different from the most indiscriminate use of these terms to-day, I argue that they have to be attributed to persons most cautiously since these terms have different meaning to different peoples and cultures. My primary distinctions are of the following:

1. those who show the generally accepted physical characteristics of old age, but who are capable of carrying on their work, and

2. those who are incapable of work, whether they are bedridden or not.
In Nepal, retiring age for a person is 60 years in government service and 63 years in university service. The elderly who are incapable of doing any work need to be specially understood because of their dependence upon others for physical, emotional and medical care.

\section{The Family: The Man}

In the Nepal, by the time a man passes the age of 50 , he becomes an authority figure, having access to the managerial tasks of the land and the agrarian resources of the family, having control over the subsistence of tenants and laborers and having the authority of a father and grand father incharge of the economic and emotional needs of the problems, including those of the nephews and nices. Maintaining the joint family was the established practice of the household, the preconditions of which was to have enough agricultrual lands to support several generations.

\section{The Family: The Women}

The wife gains prestige and recognition with her husband, although, her social mobility is restricted according to her community position. In all the functions of her lineage and related lineage she holds a highly respectable position, which gradually increases according to her increase in her age. She is an authority figure especially to her daughters and grand daughters, whose needs are met through her direct or indirect intermediary role with husband. She also manages the "servants who work inside the house and meet the seasonal obligations towards them. Such obligations include offerings of food during famiiy function of both the master and the servant and help rendered to the servant's family during life cycle ceremonies. Women in Nepal receive especial devotion from their male children, whatever may be their personal and social position. This devotion reaches the point of worship, as if towards a deity, along with the old women's increase of age, and when the women becomes 
bedridden, and later dies. III treatment of old woman by her husband is irreligious The wornan shows onermous tolerance to her hushand's misdeeds, including his extramarital adventures. Usually in higher castes and prestigious people divorce is never thought of by either partner. A significant outcome of the triangular relationship among husband, wife and children is that they mutully reinforce the attachment for each other economically and emotionally

\section{The Social Integration of the Elderly}

In Nepal an elderly male is socially active a as leader of village affairs, including in the settlement of disputes, arrargement of marriages and supervision of life cycle ceremonies such as those of puberty, initiation, birthday marriage and death. The greater the wealth of a person the larger will be the patrorage that he gives to the local village affairs His social prestige and recognition become enhanced by the sanity and maturity of his social behaviour, especially in rendering help to the needy, as well as the frequent feasts he holds for the member of the village and the hospitality that he renders to the persons who visit the village.

The Hindu belief system has important consequences and insists that a man whether husband, son or even uncle, is caretaker of the women in the family. This belief is crucial with reference to the elderly husband's economic and emotional protection of his life.

\section{Tradition in Caring for the Aged:}

The care and honor given to the elderly in traditional Nepal is structured through socialization. Children are brought up to treat the grand parents as if they are deities. During auspicious occasions such as during alphabets learning (Saraswati puja) and for the atonement of misdeeds children are made to pray to the elderly for blessing and forgiveness. Children and visiting relatives fall at the feet of the elderly and pray for blessings. During Dasain festivals especially elderly aged persons are revered and are to be respected first.
Children are Brought up with the conviction that not taking care of the needs of the elderly, showing disrespect to them and doing of speaking any thing that would emotionally hurt them, all constitute sins which may not even be atoned.

In Nepali society the girls are disciplined to care for the old because when they get married and are observed in their husband's households one duty that they have to perfo$\mathrm{rm}$ is to take care of the needs of the old father-in-law and mother-in-law. If a women shows any disrespect to her father -in-law or mother in-law, her husband, other members of his household and even neighbors will not excuse her.

The elderly in Nepal play the most active part in the socialization of children. A good part of the socialization is done through story telling, of which their life stories and those of ancestors become dominant. As a result the children are integrated into the family and society by developing associated cognitive structure in them.

Children grow with awe for the knowledge of their grand parents and are deeply attached to them because of the love and care they give to the grand children. It is expected in Nepali tradition when people are old they will be respected, obeyed and takan care of. Even today the old people retort to the young ones that "they may know much that is in books, but we know the real things that come only with experience".

In Nepali household when the father becomes older, more and more family responsibilities are assigned to the oldest son. Finally, the son inherits the managerial responsibilities of the family when the father is totally incapacitated, bed ridden, or dying. It seems to me that the tradition of inheritance is a major economic and political factor that contributes to the loyalty and attachmont of the children to the aged parents, especially the father.

\section{The Social Honoring of Dying Elderly}

When a man or women is completely incapacitated by illness such a person will be attended at all times by one or 
mope members of the family and will be visited continuously by relatives, friends, and members of the village. Elderly in traditional Nepal live as an integral part of the family and society, and death according to the belief system.

\section{The Elderly and Health Care in Traditional Mopal}

There is a highly developed indigenous medical system in traditional Nepal (Ayurveda) that meets the health care needs of the elderly. There are organic medicines to treat senility and rheumatism, the two major illness of the elderly. Specialized diet and oil massage are givan regularly. Religious fasts, prayers, and meditation contribute to physical and mental health. Above all, the harmonious and congenial relationship of the elderly with the family and the society at large, with honor and recognition, is crucial for the biological and emotional well bei$\mathrm{ng}$ of the elderly.

The traditional Nepalese gerontological model is that of preindustrial agrarian culture. The old live and die integrated within the family and the village society, because the management of the economy, redistribution and family organization are all determined by the infrastructural conditions of the agrarian economy of preindustrial technology.

\section{Nepali Structure of Family}

The family in Nepali Society is the fundamental multipurpose organization for many of the principal life functions of the individual or society. The family is the bearer of virtue and of public reputation: a mans's reputation is linked with that of the family and with his own relationship. Family is also the economic unit.

The joint family system was the familiar system from ancient times. Though this system has by now shown the sign of breaking because of modernization and development activities, still in many parts or rural and urban Nepal joint family system is still alive. In the past joint family system was stronger and broader. Not only the parents' children, brothers and step brothers lived on the common pioperty sometimes it also inclua ded descendants and collateral upto many generations.

In the joint family there was immediate help to tide a member over illness, there was an increased efficiency of pooled labour and economy of a single kitchen Domestic rites and celebrations are still practised in joint families. Each person is seen by others in the rural and urban areas in the light of his family's reputation. When a person comes to a major life transition such as marriage, the reputation of the family weighs heavily in the decisions that ate made. He is much advantaged if his family is large, hamonious and joint thus demonstrating that its membors are reliable worthy people.

Age and sex are the main ordering principles in family hierarchy. The men are regarded as having more decisive authority as compared to women and elders have greater authority than young. The patrilineal principle defines man to cooperate most closely in a family and lineage group. The family ideal governs the relation between close male kin. Each male is entitled to an equal share of the family property from his father. Women, whether in the status of daughter, wife or widow, are entitled to maintenance by their male kin, but under the traditional rule they had no other vested rights in the family property.

Though the joint family system was a ideal form of family structure in Nepalese society it has began to be disrupted because of job and other income generated activities and shifting of living place to different parts of the country. This has resulted in the breaking up of joint family which has tremendous impact on the security and care of aged person in the families.

Previously the joint family provided managerial personnel for the agricultural land holdings and was supported by the administative system in which the eldest male becomes the head. In that situation elderly persons maintained the economic and social power of the family by preventing fragmentation and 
by maintaining continuity. The family has become a multicomplex institution, included in it the needed religious institution or religious affiliations, with ancestor worship. The elderly are still regarded with respect by the family and society in transitional Nepal. They are taken care of by at least one of the children in most cases. and they still enjoy favorable recognition, although not to the extent of traditional Nepal. Seasonal rituals to the ancestors are still performed.

However, at the same time neglect of the elderly, a situation that rarely happend in agrarian culture, has begun to occur.

\section{Action to Strengthen Traditional Value}

Traditional adherence to customs, usages norms and values are still in continuation in many parts of Nepal. But due to onslaught of Nepali cultural values by western values, obedience, respect and obligations to elderly people are weakening due to the impact of western life styles and amenities. The proportion of aged people will be increasing over the years in the future. With age, one's health goes down, physical and mental capacities may start failing. In short, in the old age (60 above age group) one is likely to grow more and more helpless, and so dependent on others in the day-to.day living. Usually such help is expected from one's children/spouses. But many in urban areas and to some extent in the rural villages, the grown up children have their separate households and may not be able to give this kind of assistance. The spouses may themselves be aged and therfore of little help, on the contrary, they themselves may be in need of help. Therefore the society should come forward with succor. The government has to provide old age pension scheme. The homes for the aged should be established where aged will be looked after by someone. The aged should be assured of security, warmth of care and love so that old people would not feel depressed and deprived. And in this lies the core of the problem. It is human nature to look forward to a life of contended repose in a graceful home of love and affection for which one has worked all life. Instead what the old find is formal care and loneliness. Their sunset years appear to them as an appaling abyss of gloomy problems rather than the mellow glow of hope and peace. The problem of old age in the modern society seems to defy happy solution It is a big challenge to the social scientists and humanists and in the west they have prepared themselves to meet it with determination.

As Nepal is king some strides towards industrializa. tion with the consequent urbanization and revolutionary changes in the political system and in the socio-economic structure it would be wise to assess the condition of the aged and ageing to gauge the nature and proportion of the problems that attend the transformation. Only then we will be able to put the proble$\mathrm{ms}$ in their proper prospective and to find effective means to tackle them. Full and clear grasp of the whole problem is basic to the successful planning in this regard. The growing momentum of the accelerating progress of development is shaking simultaneously from the traditional mooring, all the section of the diverged people in diverged ways, and leaves a trail of problem in its wake. These problems are big, deep and many and each section insists on the highest priority and quickest action for the problems that affect it in particular. Study of gerontological problems in Nepal has to start from the base, which should avoid the assumption that it is the same in character and degree as in the western developed countries tempting analogous treatment.

\section{Institution for the Aged}

As life expectancy grows, the changes in the dwelling places contribute to the instituitonal care and service to the neglected old people. These institutions in developed countries range from the home for the aged, and the nursing home for the disabled to mental or geriatric hospitals which have appeared mostly in United Kingdom. But the quality of life in these centers is poor and rigid limitations, lack of recreation and contact with the outside world suggests a cosntant battle with dehumanisation of the environment. It is to be realised that favorable psycho-social environment needs to be created by attractive environment and personal warmth of the administrative staffs. 
Recent research in several countries has confirmed the favorable effects of thoughtful design on the physical activity and social behaviour of the inmates and the visitors. Institutionalization is less likely where traditional family attitude persist. It should be the last resort and then improvement should be sought in its staff, performance and service.

There is a bewildering series of nomenclature for planned housing of different types : council housing, adopted housing, Hongkong housing for the old people and their sheltered family housing, grouped housing in the U. K; Congregated housing in the U.S. A. and alternative housing. There is danger that rapid expansion of planned housing may adversely affect the quality of family life.

Much less research has been done on community relationships. Even then, it appears that in the poorer areas or growing cities, services should be family oriented rather than being elderly-specific. There is however, one danger to such a policy: it may exclude the elderly without family and it is they who really need help

In rural societies the family takes the full responsibility for its aged members and the community, of the unaffiliated. The home for the aged with services for mild functional incapacity is the first major age-specific

\section{Residential Alternative to Emerge.}

The next is the nursing home where medical and nursing services are available. The young people who migrate to urban areas, however, continue to feel the obligation to support their elderly relations. Thus, national policy cannot be determined by the single conclusion that intergenerations living is always the best.

The study of natural history of residential types may heIp a developing country like Nepal to foresee and modify the future changes. While in rural societies, family and neighbourhood take the full charge for the aged, hospitals replacing the almshouse are the first mode of caring for the aged not supported by family in urban areas. Though poverty will hinder institutionalization in Nepal, the use of institution to house the healthy old may be useful. Home for the aged and nursing homes may support the old people with physical problems at lesser expense.

In Nepal, it is urgent to consider more effective alternatives for the care of the aged such as:-

(1) reinforcing the continuity of family care and the organization of low technology social support to supplement family care, and

(2) directing labour resource towards service functions.

An option is the state support on a mutual-aid basis rather than an institutional basis. Family and face-to-face support may be suplemented by cash disability allowance and attendent allowances. Family income may be enhanced if some member choose to care for the grand parents at home. A second option is the policy or support for organized low-technology home services that provide more humane and cost-effective care. If the attractiveness of the wage market, which cannot absorb all workers can be offset by socially recognized service labour, families can be aided by government for retention of the task and responsibility. Public funds could encourage rural groups and family members to live together or close to each other so that bonds of love are maintained even in urban settings. Housing policy can be formulated to stimulate intergenerational occupancy and tax incentives to ensure that the families choose to provide personal care for the elders are worthwhile to try instead of a rapid jump from traditional culture to depersonalized provision of entitlement based social services. Developing country like ours might find out the means of retaining as much of the old fabric of human relationship as is possible.

There is one ethical note to be remembered. The wage economy gives an individual right to do what he or she chooses, but obscures the obligation attached to freedom. So, developed 
countries react against the tax-supported social provision for the helpless. The pracical decision in developing country like Nepal ture rathe caring mechanism that exist in its culnism.

\section{Existing Organization and Institution: A Case of Bridhyashram}

For the aged existing organization and institution seemed to be negligible. The established organization and institution for the welfare of the aged is not found to be in the priority list of the government. There is a Bridhyashram (Senior Citizen House) at Pancha Dewal run by the Ministry of Labour and Social Welfare. This Bridhyashram was begun since 1975 , prior to it, in this place There were also some men and women, along with poor children. for begging. Actuly for food and lodging and would go en late king Surn back to the year 1870 whdisabled persons. But send their servants and wor on Ranas and other aristocrats would them. It was not unable to serve institution systematically until 1980 when this Welfare from taken over by Ministry of Labour and Social run than what it was in 1980 . Study revealed that it is better ple. Out of 170. there are 76 There are at present 170 aged peo-

which these aged persons belong Biswakarmas. Most of these, Gurung, Lama, Giri, Puri and 3 Most of the aged living in this people belong to higher castes. Bagmati zone, rest are from social welfare centre are from istry of labour \& social welfare hastricts. H. M. G., Min$8,35,475 /$ for the year $199: / 1992$. medicine which is not in the center are sick. Som of the aged living disabled destitute. Some paralyzed, blind and esa's Missionary cared by Mother Tercared by the charity. These lots are medically seen and 40 seen by H. M. G. Ministyr of labour and social welfare, there is only one Kabiraj (Ayurvedic) and the care is not found to be satisfactory. It is because Missionary sisters help from within and government employees just see it from outward. The living environment is not well. Sanitation is poor and sewage system is worse. Dirt and polluted water was found inside the courtyard of the center.

During coming financial year the centre is going to be shifted to Sankhamul where it is reported that building is already constructed but the aged people and the employees feel that building is not well planned and has great defect. They viewed, most of the residents of the welfare center are not willing to shift because they want to stay near Pashupati \& Arya ghat. They are religiously attached with this place. Moreover new building at Sankhamul has toilets only in one side out side, the building so the aged are bound to be in trouble. Also they feel the spacing between the huts and rooms are very small which will put them in problem. However, the concerning authority must see it before they are shifted to new places.

There are such centers in Biratnagar and in Dhankuta for the old people but are not functioning well. Some centers are there in Rajbiraj, Birgunj, Butwal, Panchkhal were only chiIdren are taken.

High demand for such Bridhyashram or nursing home is experienced in Nepal. Many come to visit the center and find improper management and would go back with hopelessness. There seems to be dire necessity of such centers and nursing homes. For this three types of nursing homes or Bridhyashram can be well planned. One type for poor destitute, second type for the people of low income group who would like to stay by paying less amount, the third kind of nursing home could accomodate those rich and educated people who are willing to pay more. 
The present situation tells us it is the need of the day. For such development of institutions for aged, existing NGOs and social workers and their agencies should come forward and government must help them for strengthening further.

\section{Other Situations in Nepal}

Nepal is a poor country, with per capita income being one of the lowest in the world. This poverty is greater in our rural areas. The semi towns and cities also have their poor living conditions. Though the joint family still survives in the rural areas, the chances are that the well being of aged in the indigent families would be sacrificed first. The social planners have to take special note of this possibility.

In the cities category of retired person is likely to swell in number. They will have problems of their own. Their income would fall suddenly and steeply with retirement. Pension, provident fund, gratuity received by them on retiremet would not be enough to make for the loss of the earning while in service (soodan, 1975). Continuous monetary inflation will further reduce their real-income and add to their hardship. All these presage a mounting economic pressure on the retired age. Destitution is wider and more pronounced in the rural areas. The larger part of the population is engaged in an unequal struggle with poverty, and of these unfortunate, the aged are the hardest hit.

The observation and experience tells us that difficulties in physical movement, failing of sight and hearing, heart ailments, diabetes, arthritis and all that assail the human physique in the old age, prey upon the aged here singly and more than one at a time Their ravages are promoted and aggravated by poverty keeping nourishment and treatment out of reach. Over crowded hospitals and health-post which again most at inconvenient distances and few and ill-equipped can not offer special room and care to the aged of the lower and middle groups. The getting of medical help is a harrowing adventure-a despair. One has to travel long and tiring distances, spend weary hours in unending ques and then on reaching the counter if lucky. meet an unfriendly and often surly reception. One can well imagine the plight of an old person and ailing.
The aged face much worse situation in the rural areas. When in the cities and towns at least hospital, private clinics and doctors are within reach. But in the rural villages, hospitals and health posts are few and far and mostly in neglected state. To reach hospital or to get a doctor means money and the people are too poor to afford it. So to suffer and die without even the prospect of a healing hand is the lot of the rural aged.

Health coverage is the responsibility of the government. But even the minimal achievement in this regard is straining its resource and efforts. The aged deserve greater health care than others. This ethical duty is sure to prove to be a big problem as time passes.

\section{The Sucial-P sychological Problems}

In our country, in the past, age was respected and valued, for aged represented practical wisdom born of long experience and maturity of mind. The old also were the depository of established laws, tried conventions and rules of life. There was a more tangible ground for the dignity enjoyed by the aged. Agriculture had been the only respectable occupation of the corrm on people, to own land was highly regarded. The owrers held titles till death and by this was looked upon as the ultimate master of the earning of the family. This higher status of Pater familia secured high esteem in the society/community.

School education with modern knowledge coupled with semi industrialization and the consequent urbanization has struck at the roo: of the traditional village society and attitude. The traditional wisdom is failing to guide in the changed style of life and the demands of modern economy. Our joint family Ianguishes in the industrial atmosphere of the towns. The children of the old parents would live away and apart from their old parents. As a consequence, the old, even if in a lesser degree in the villages than in the towns, do not command any longer ready and willir g obedience, care and services from their children. This is the general impression. 
With the decline in the standing with the family and so with the society the old would be liable to be subjected to material as well as psychological depression at the personal level. There may also be other contributory factors to add to the misery. One such may be the loss of conjugal partner, friends and other life-long associates. This, along with physical decline, would deprive person of social contacts he or she been accustomed to the isolation would tend to breed morbidity and frustration. One feels oneself void-lost with no hope for escape from the gloom. And then there may be the growing scare of death, closing in upon. All these may culminate into a consuming pain rendering every thing in life bitter and hostile. So there is likely to be mental illness among such aged and organized thinking and efforts should be made in this regard of social problem.

\section{Conclusions}

In a subsistence economy like ours, there is hardly any scope for the majority of people in rural areas to save or invest for old age support as is possibie in the developed world and in urban areas in this country. Under such circumstances children of many of them were serving as old age security. The lack of suitable alternatives to children as a source of security in old age or the difficulties and uncertainties in taking advantage of them even if they existed is one of the factors for the frustrating experience of the birth control programmes in the less developed countries. If the population pressure is to be reduced in the country the only choice left open is to accept the small family norm by adopting one or other method of birth control. To achieve this it is all the more important now to try to reduce the reliance of parents in sons as old age security.

The pension scheme even if introduced in the country will be of a walfare maasure for the destitutes only. If the pen-

Note:- I thank Prof- Kailash Nath Pyakuryal, Department of Sociology and Anthrophlogy. Tribhuvan University for his comment and inspiring suggestions regarding the final prepartion of this paper. sion schemes can be extended to all the aged, with higher amounts paid to the couples with no son to support than that paid to such as have, it would certainly go a long way in reducing the parents total reliance on sons in the years to come. Birth control programme accompanied with old age security schemes would surely lead to substantial decline in the rates of population growth.

\section{Suggestions}

1. The need of national attention for the care of the aged must be viewed with great importance by the society and concerned government agencies.

2. The aged above 60 years after all constitute a mere $5-6$ percent of the population, and by far a larger part of them are spread over the wide countryside where the family and the community still carry on, by and large the old tradition of caring for the old. This has helped in obscuring the reality from view.

3. Eradication of poverty is rightly a problem of much greater urgency and its solution will solve the problem of the aged at least in its economic aspect.

4. Pension scheme must be extended to destitute. The social workers may be inducted in the implementation of the sch eme and should work in the field.

5. The establishment of the homes and nursing homes sho uld be given priority in the social workers' plannings. The women, however, should have separate homes, as their problem is of different kind.

6. Gerontological study must be done first to identify the social problems of ageing in Nepal, by anthropologists and sociologists.

7. A special medical service for ailing aged should be made in the hospitals It can also be recommended that it may not be too much of trouble to have special ques for them at the 
out door patient counters, transport ambulance servilee wh. en distances are great and journey difficult.

8. A counselling programme may be introduced to advise the aged employees how to adjust themselves in their changed circumstances.

9. NGOs should be encouraged by every means when they wish to help eradicate problems of ageing in Nepal.

10. Social security planning must immediately be dona.

\section{References}

1. Arensberg Conard M. 1968. The Irish Countryman;An Anthr opological Siudy, Gerden City, New York: Gerden city Press.

2. Atchley, Robert C. 1977. "The Scope of Social Gerontology" The Social Forces in Later Life: An Introduction to Social Gerontology, Belmont, California, Wardsworth.

3. Clart, M: and B.G. Anderson. 1967. Culture in Ageing Anthropology of Older Americans. Springfield, Illinois: C. Thomas.

4. Chandra Dare 1983. "Some Psycho-socialAspects of Ageing" Paper Presented at the National Seminar on Psycho-social Aspects of Ageing. Terjupati June, 1983.

5. Chandrasekariah, $K 1985$ Problems and Issues in Ageing: A Sociological Analaysis. Paper Submitted to the Internation Seminar on Population Ageing in India, Trivar drum, 1983.

6. Chandrik, P. and Anantharman, R.N. 1982. Life Changes and Adjustment in Old Age. Journal of Psychological Res earches 26: 137-141

7. Desai, K. G. 1985 "Situation of the Aged in India. in Journal of the Indian Anthropological Society, Vol. 20, No.3

8. Kapadia, K.M. 1968. Marriaga and Family in India. Calcutta and London: Oxford University Press.

9. Marda, D. 1978: Ageing in Eastern Society, In The Social Challenge in Ageing. D. Hobman (Ed) Croom Helm, Londo11. pp.45-72.

10. Soodan, K.S. 1975: Ageing in India, Minerva Associates Private Limited, Calcutta.

\section{Religion, Society And State In Nepal}

\author{
Dipak Raj Pant
}

\section{State of the Religion}

Nepalese society is made up of a variety of small, comprehensive units. Some of these units are "natural" (1), in the sense that these are composed of members related among themselves by organic ties, i. e. common descendence, kinship, marriage, common territoriality etc. Family (Nep. Parivara), clan or closest kinship group (Nep. Khandan, Khalak, Gharana), caste (Nep. Thari) and, to some extent, ethnos (Nep. Joti) reflect the natural grouping in Nepal. Among the additional factors for social grouping religion is perhaps the most important one.

The religiousity of a group is determined, in the first place, by a characteristic subjective (individual or collective) experience of the mystery (the "unknown" or the "holy"). It is a basic datum which can not be properly explained in rational terms and it is certainly not reducible to the influences of any external (historical or environmental) factors. In the second

The author is a previous associate professor (on contract). Central Department of Sociology and Anthropology, Tribhuvan University, Kathmandu. 